\title{
Playing host to evolution
}

\section{Infectious Disease and \\ Host-Pathogen Evolution \\ edited by Krishna R. Dronamraju \\ Cambridge University Press: 2004. 384 pp. $\mathfrak{E} 65, \$ 95$}

\section{Sunetra Gupta}

It is apt that in the year that marks the 40th anniversary of the death of J. B. S. Haldane, we should have a book on host-pathogen evolution that so explicitly acknowledges the debt this field owes to him. I refer not just to his ideas regarding the influence of infectious disease on host evolution, but also to his tireless efforts to inject rigour into the language used to describe it. "Words," he said, "are well adapted for description and the arousing of emotion, but for many kinds of precise thought other symbols are much better." His genius lay not only in defining a set of problems that would keep so many of us gainfully employed, but also in identifying some of the tools with which to try and tackle them.

The book opens with two wonderful essays. The first, by James Crow, locates Haldane's ideas on disease and evolution within his multiple and diverse intellectual occupations. The second, by David Weatherall, follows the fascinating trajectory of Haldane's 'malaria hypothesis' - the proposal that the high frequency of the blood disorder thalassaemia could be attributed to selection by the malaria parasite Plasmodium falciparum. "It is doubtful," Weatherall comments, "whether Haldane could have had any idea of the large industry that his short paper of 1948 had spawned." So, just how well does this book exploit this?

Sara Tishkoff and Brian Verelli's chapter on glucose 6-phosphate dehydrogenase deficiency and malarial resistance in humans, and Peter Zimmerman's discussion on the the link between the Duffy blood-group antigens and resistance to Plasmodium vivax malaria, fit neatly into the scheme. The chapter by Alain Dessein and others on the genetics of host resistance to Leishmania and schistosomes carries the theme into the realm of other parasites; Tom Little and Dieter Ebert's summary of their elegant work on Daphnia and its diminutive parasites broadens the context to include a different host. The latter is a model chapter, and refers intelligently throughout to the evolutionary principles articulated by Haldane. Extending some of these principles to public-health concerns, the chapter by Andrew Read and co-authors, which outlines with due caution their theory that vaccines may increase virulence, also finds a rational place in this collection.
Newton Morton's rather sketchy chapter on genetic epidemiology provides a useful comment on both its history and its methodology, but might have more properly belonged in the introduction. So too would Michel Tibayrenc's endorsement of the Human Genome Diversity Project as a means of answering certain critical questions surrounding susceptibility to infectious disease. Finally, extending haldanesque thinking to diseases of unknown origin, the chapter on diabetes by Kyle and Gregory Cochran is a refreshing addition to a book that could have restricted itself to diseases that are obviously infectious.

But set among these are several chapters on issues that do not easily integrate into the general theme of Haldane's legacy. Two excellent, detailed chapters on the evolution of plasmodia could claim to have come in on the malaria ticket, but those on the evolution of influenza and cholera, although of high quality, do not find their natural home here. More inexplicable is the inclusion of a chapter on regulatory DNA.

There is a good reason to be so concerned about theme. The chapters are based on peerreviewed work that has appeared in highquality journals, and the authors have, almost without exception, devoted time and effort to put their findings together in a clear and intelligible manner. But who will read this book? Long gone is the age where "definitions first appeared in books rather than articles", to quote from Morton's chapter. The purpose of putting together such a book is surely to inspire students and teachers of biology at an advanced level, and thematic unity is a critical element in achieving this goal. In this respect, the book's lack of continuity is detrimental to the ever-diminishing dialogue between scientists and eager students of science. This gap is unlikely to be bridged

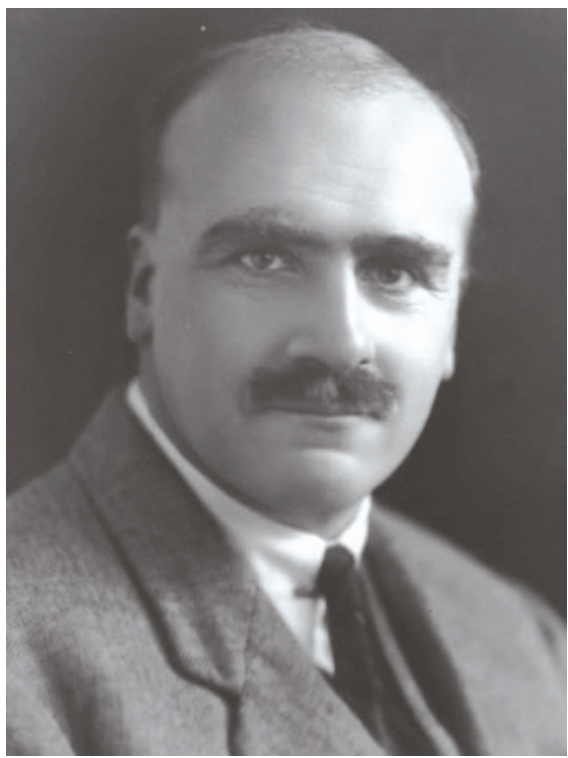

J. B. S. Haldane laid the foundations for studies of how infectious disease affects host evolution. by expressions of embarrassment at the "Eskimo" custom of lending their wives to dinner guests (in the concluding chapter by Luca Cavalli-Sforza), even if the reference is to the Lonely Planet guidebooks. One can imagine such a gross example of the commoditization of women appearing in one of Haldane's essays for the Daily Worker, but it is doubtful that it would have found its way to the part of his mind that dwelt upon disease and host evolution.

Sunetra Gupta is in the Department of Zoology, University of Oxford, Oxford OX1 3PS, UK.

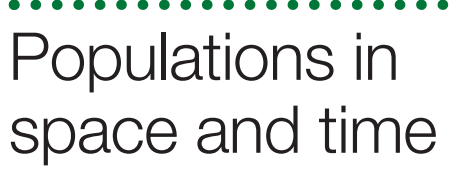

\section{Ecology, Genetics, and Evolution} of Metapopulations

edited by Ilkka Hanski \& Oscar Gaggiotti

Academic Press: 2004. 696 pp. \$54.95, £36.99

\section{Alan Hastings}

Edited compilations of papers can often be the only place to find an integrated and timely view of a rapidly developing subject area. This volume on metapopulation dynamics is the third to be co-edited by Ilkka Hanski in the past 15 years. Given the editors' decision to commission new chapters, rather than to revise the previous books, it is perhaps best to view this one not as a fully developed, integrated view of metapopulation dynamics, but rather as the latest, extended issue of a journal perhaps entitled 'Trends in Metapopulation Research'.

The concept of metapopulations is one way to include the role of space in population dynamics. The original models for metapopulations focused on the fraction of occupied patches or habitat as the measure of population size, and included only colonization and extinction as processes, but more recent work has become increasingly sophisticated and general. Any treatment of the subject needs to ask whether biological questions are being forced into the metapopulation framework of local colonization and extinction when other approaches to spatial dynamics might be more appropriate, and whether the metapopulation approach should be extended - is it more than a way to understand butterflies?

The book's overview chapters focus on connecting metapopulation research to other advances in studying spatial ecology, including continuous-space stochastic models and landscape approaches, but in my view this section could have been extended. Some connections, such as those to recent work on ideas of scaling in spatial ecology, are not discussed in enough depth.

Much of the current ecological work on 
metapopulations can be traced back to work by Richard Levins in 1970, but similar kinds of issue were raised in a genetic context by Sewall Wright as long ago as the 1930s. Also in the 1930s, A. J. Nicholson and V. A. Bailey, along with G. F. Gause, raised ecological questions in their classic contributions, but without using the term 'metapopulation'. Yet, as discussed in the introductory chapter, research in this area has increased sharply in the past 15 years, making any attempt at an overview difficult.

In contrast to the earlier volumes coedited by Hanski, this one gives almost equal weight to the evolutionary and ecological aspects of the subject. There are also fewer overviews of metapopulations, so this is not a volume to teach newcomers the basics. Instead the emphasis is on more specialized topics and applications, including conservation and reserve design, disease and pathogen dynamics, and speciation.

The papers in this volume use primarily theoretical and conceptual approaches. Readers looking for data-heavy contributions to help place the conceptual work in context will be disappointed. Also, although both genetic-evolutionary and ecological questions are considered, few contributions truly synthesize these different disciplines.

Not many readers are likely to read this massive volume from cover to cover, but it should prove useful as a reference book. There is good coverage of enough important recent advances, such as the use of coalescents and the study of metacommunities, so at least parts of the book will be required reading for students and researchers in spatial ecology.

Alan Hastings is in the Department of

Environmental Science and Policy, University of

California, Davis, California 95616, USA.

\section{Facial diversity}

\section{An exhibition in London features the changing expression and representation of the face.}

\section{Jonathan Cole}

The face is both a unique identifier and an embodied read-out of emotion. We look through it to see - or think we see - personality. And we use the face as a means of expression, to communicate with others, with and without words. Yet we now see so many unknown faces, in the street and in the media, that sometimes we gaze on others with a detached curiosity that can never be satisfied, seeing but not engaging. Sandra Kemp is well aware of this; her wonderful exhibition, which is presented by the Wellcome Trust and can be seen at London's Science Museum until 13 February, invites us to look and admire faces but also, constantly, to question and to feel.

In the first room, a series of scientific representations explore where the face begins and ends. Contemporary images from scans of faces and of blood vessels in the face and head combine accuracy with beauty. An 1837 drawing of a dissection has presence and poise. Opposite these are ancient, exquisite sculptures of faces, presaging Picasso and Modigliani. The scientific and the artistic complement each other in content and aesthetics throughout.

At the heart of the room is a collection of masks, used to conceal and transform identity because of disease, in Japanese Noh theatre, or to hide the face of an executioner. Beyond this are pictures of facial injuries from the First World War and the fitting of prostheses for camouflage. Across the room, a middle-aged man in a tweed jacket has his enucleated eye socket dressed.

A video installation by Chris Dorley-Brown has two screens. One screen shows a series of 10-year-olds who were given 15 seconds to express themselves in their faces; the other screen

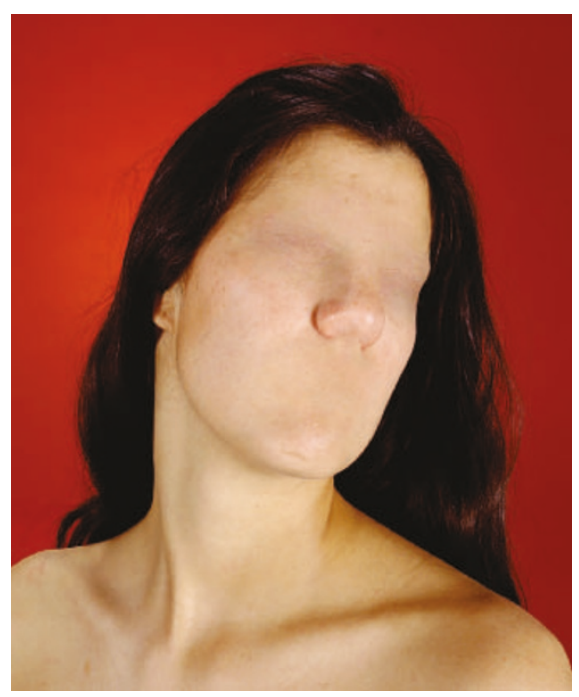

shows the same people doing the same a decade later. At the age of 10 they were animated, alive and playful, but by 20 they were concerned, knowing and apparently less, or at least differently, embodied in their faces. There is also a short series of people with facial disfigurements, each enjoying life and wearing a big smile.

Max Factor (the man behind the brand) appears trying in vain to measure facial imperfections with steel gadgetry, as shown below. Elsewhere, a tattooed face shows too much, and a Geisha reveals little. Hollywood's monsters lurk in a series of small photos. Dolls lie in glass cases; one has several faces, seen by rotating the head, the posh face happy, the poor miserable. A computer gives the next doll facial expressions and responsive emotions - but is she comforting or scary?

We are given a view of recent developments in the recognition of facial features and expression before we see examples of how new technology can alter our perception of the face. We meet Kaya, a virtual model, given imperfections to improve her humanity, and an avatar who talks to us face to face, a presence from a strange virtual world. Then we are seduced by a digital Marlene Dietrich.

Kemp shows us that we have always portrayed faces in culture, often distorting them, but that, through new technology, we will do this even more powerfully in the future. Might this alter our views on facial attractiveness, or even alter the semiotics of facial expression? This small gem of an exhibition delights and questions throughout. It is complemented by an excellent book, Future Face by Sandra Kemp (Profile Books, $£ 12.99$ ), and an interactive CD.

On the way out we pass a gleaming black-and-white photo of a man yawning, an image that is almost unnerving and completely contemporary. Extraordinarily, the original was sculpted in the eighteenth century. Where, Kemp asks, will our imagination and new technology take facial representation in the future? Jonathan Cole is at the University of Bournemouth and is a clinical neurophysiologist at Poole Hospital, Longfleet Road, Poole BH15 2JB, UK. 